\title{
Batch, absolute and relative fecundity of the Bali Sardinella, Sardinella lemuru (Bleeker 1853) from Balayan Bay, Batangas (Philippines)
}

\author{
Alicia Ely Joson-Pagulayan ${ }^{* 1,2}$, Steffi Mari Arceta ${ }^{1}$, Agatha Carine Banaag, \\ Catherine Macalintal ${ }^{1}$, Carinna Andrea Reyes ${ }^{1}$, E Luis Maria B. Garcia ${ }^{3}$ \\ ${ }^{1}$ College of Science; ${ }^{2}$ Research Center for the Natural Sciences, \\ University of Santo Tomas, 1015 Manila, The Philippines; ${ }^{3}$ Institute of Biology, \\ College of Science, University of the Philippines-Diliman, Quezon City, The Philippines
}

Sardinella lemuru (Bleeker 1853) is a tropical species found in coastal areas. In the Philippines, it is abundantly caught in marine areas like those in Balayan Bay, Batangas. The increasing demand for the species has led to previous reports on the decrease in the annual fish stock [1]. Knowledge on the reproductive biology of the fish, such as fecundity, is important to determine the status of the fishery stock and help in the proper management of the fishery resource. In the present work, fecundity estimates of 42 gravid ovaries from female fish samples (mean total length of $152 \mathrm{~mm}$; mean eviscerated weight of $28.4 \mathrm{~g}$ ) were conducted. Absolute fecundity ranged from 4,507 to 43,733 eggs while batch fecundity was in the range of 1,035-25,560 eggs. The relationships of fecundity (absolute and batch) to both body length and body weight using linear correlation indicates that absolute fecundity show a moderate correlation with both fish length $\left(r^{2}=0.326\right)$ and fish weight $\left(r^{2}=0.290\right)$. A similar trend was observed with batch fecundity versus length $\left(\mathrm{r}^{2}=0.248\right)$ and that versus weight $\left(r^{2}=0.230\right)$. The data on relative fecundity estimates reveal a range of 95-1262 eggs/fish $($ mean $=486+/-225)$. The high gonadosomatic index (GSI) observed indicate that the spawning period of $S$. lemuru occurs from the months of November to February, peaking in December and January. Ovarian samples representing mature to gravid conditions reveal different stages of vitellogenic oocytes. This continuous development of yolky cells that will be eventually spawned suggests that $S$. lemuru exhibits an indeterminate annual fecundity.

Keywords: Sardinella lemuru, batch fecundity, absolute fecundity, relative fecundity, Balayan Bay

\section{INTRODUCTION}

As the Philippines is an archipelagic country, fishery serves as one of the major sources of livelihood for many Filipinos [2]. Sardines is one

*To whom correspondence should be addressed: ajpagulayan@ust.edu.ph of the dominant landed pelagic fish group in the country, with the Bali sardine, Sardinella lemuru, as one of the most abundant species [3, 4]. Sardinella lemuru can be found in several areas in the Philippines such as in Zamboanga, Palawan, Pangasinan, Sulu, Butuan, Bicol, and Tawi-Tawi [5]. 
Sardines are characterized with a constricted, silvery, streamline body, protruding scales and a single soft-rayed dorsal fin. Their dorsal fin is located at the midpoint of the body, with the anal fin found anterior to the dorsal fin, and the pelvic fin behind the origin of the dorsal fin. They have bilobed, non-functional lungs and are known for their oily flesh, which is a great source of omega-3 [4, 6]. They are commonly distinguished by their body depth and standard length, the presence or absence of colored spots, and colored lines and fleshy outgrowth located behind the gill cover [7]. Furthermore, they can be differentiated with other small pelagic fishes by their rounded upper lip and two pronounced supramaxilla at the proximal end of the mouth.

Sardines are abundant not only in the Philippines but in other countries, as well. For the past decades, S. lemuru has been one of the top landed fish in the Philippines and has played a major role in the country's domestic economic revenue [1]. It has also provided food security among the local community and a source of protein to Filipinos. However, as the population steadily increased, the demand for the fish also increased, such that the species may be threatened with overexploitation. The shape variation at maturity among males and also in females, as well as the observed population decline in 2009 may be attributed to fishing pressure $[8,9]$. Changes in fecundity, size at maturity, and spawning season may also change when a fish population is threatened. At present, there is a lack of information on these aspects in the biology of $S$. lemuru in the country. The present work deals with fecundity estimates of the species. Data on the number of eggs released by $S$. lemuru may be useful in understanding variability in fisheries production that threaten livelihood and food security among coastal communities [9]. In addition, estimating the fecundity and evaluating various reproductive parameters such as body length and weight in the formulation of policies in implementing more effective methods to properly manage the population of S. lemuru. In sardines, as well as in other fish, fecundity can be used to compare between different fish species [10], to serve as a standard for assessing the state of a fish stock, and to determine whether or not the said species is overfished [11]. Basic knowledge like fecundity on the life history of any fish can be used to formulate management policies and conservation methods that may be applied to fishery resources [10] Identifying the spawning season of a fish stock can assist fishermen of the appropriate time to catch fish, allowing the species to spawn successfully. In this way, the fish stock can be maintained and overfishing can be avoided.

The present study specifically aims to: (1) estimate the fecundity (i.e., batch, absolute and relative) of $S$. lemuru collected from local catch from Lemery, Batangas; (2) determine the relationship of the fecundity of $S$. lemuru with its body length and body weight of S. lemuru.

\section{Materials AND METhOdS}

Sampling. Mature to fecund female fish were collected during the months of October 2015 to September 2016 and November 2017 to February 2018. The samples were bought from local fish catch in Balayan Bay, Batangas (Fig. 1) that are sold in the town market of Lemery. Three fish from the samples collected were brought to the Bureau of Fisheries and Aquatic Resources for species verification.

Fish measurements. The total length $(\mathrm{mm})$ of the fish was measured from the tip of the snout to the tip of the longest caudal lobe. The fish was dissected to reveal the gonads. The eviscerated weight $(\mathrm{g})$ of the fish was taken. The ovaries were removed, weighed (up to $0.1 \mathrm{~g}$ ) using an analytical balance. 


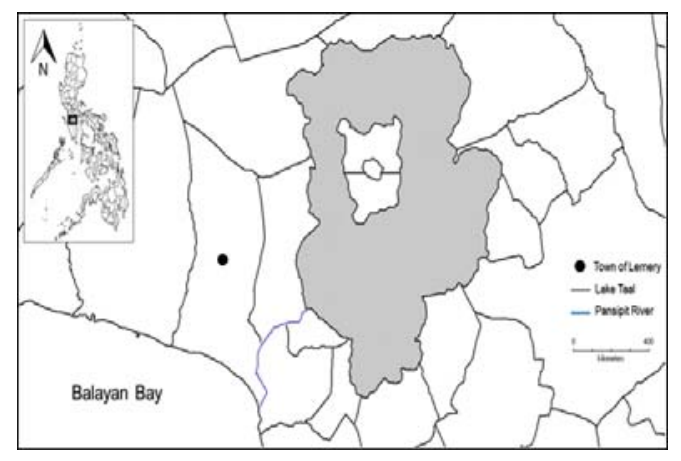

Figure 1. Map of Balayan Bay, Batangas

Gonadosomatic index. The gonadosomatic index (GSI) was determined using the formula: $\% \mathrm{GSI}=(\mathrm{GW} / \mathrm{W}) \times 100$, where $\mathrm{GW}=\operatorname{gonad}$ weight; $\mathrm{W}=$ eviscerated body weight.

Estimation of fecundity. Batch and absolute fecundity was observed in S. lemuru. The gravimetric method was employed in the laboratory to study fecundity. For absolute and relative fecundity, only vitellogenic oocytes, up to the most advanced stage (hydrated oocytes) were counted. The procedure for hydrated oocyte method [12] was followed in determining the batch fecundity.

The ovaries were dissected out from the previously weighed fecund fish with GSI 4-11\%. Both left and right lobes of the gonad were weighed and only the left lobe of the ovary was used for fecundity estimation. This is due to its larger size compared to the right lobe since. In a previous study, it was noted that there is no significant difference in maturity between the two lobes of the ovary in a female regardless of the size [13]. A subsample (.03-.04 g) of ovarian tissue was isolated from the central region. According to Pérez [14], regions of the ovary bear no relevance to the number of hydrated eggs within the ovary. The subsamples were stored in properly labeled vials and preserved in $4 \%$ phosphate buffered formalin.
Prior to fecundity estimates, the subsample was placed on a Sedgwick-Rafter counter and flooded with three to four drops of glycerin. After 10-15 min, the slide was tapped gently and the oocytes were teased with a probe or forceps to spread them across the slide. The slide was observed under the microscope and the number of hydrated oocytes was tallied using a hand counter tally. Two trials were performed and the average count was recorded. For batch fecundity, the hydrated oocytes were distinguished from the mature oocytes by observing their large size, wrinkled appearance, and translucence [12].

Fecundity of each sub sample was calculated using the formula, $Y=x(Z)$, wherein $Y$ is batch fecundity, $x$ is the number of hydrated oocytes per unit weight in the tissue sample, and $Z$ is the combined weight of the right and left lobes of the ovary [12]. The same formula was used for absolute fecundity, with the variable $x$ as the number of both mature and hydrated oocytes. Relative fecundity was computed from the ratio of absolute fecundity divided by the eviscerated weight of the fish.

Statistical treatment of data. The relationship between fecundity vs. body weight and that between the fecundity vs. body length (total) were noted in the present work. This was done in order to test the theory that states that the larger or longer the fish, the higher the estimates for its fecundity [10]. Simple linear regression analysis was applied to determine the relationship of the aforementioned parameters.

\section{RESUlTS AND DISCUSSION}

Gonad maturity and vitellogenic oocytes. A total of 42 ovaries from female S. lemuru (total size range, $127-181 \mathrm{~mm}$; GSI 4-11\%) were studied for fecundity estimates. Sardinella lemuru was observed to have a silvery, elongated body with visible scales, a black spot 
at the posterior border of the operculum and a faint golden streak at its midlateral side (Fig. 2a). Fish specimens were dissected to reveal the gonads for sex determination (Fig.2b). The ovaries were characterized in terms of (1) their gonad size relative to the body cavity, (2) their color, (3) the presence and absence of blood vessels, (4) the amount of adipose tissue, and (5) the visibility of the oocytes. The mature to gravid female had ovaries that covered threefourth $(3 / 4)$ up to the entire length of the body cavity of the fish. Asymmetry between the left and right gonads was frequently observed, with the left gonad usually being the larger of the two. The ovaries were observed to have yellow to yellow orange color. Blood vessels were noted to be large and oocytes were visible through the ovarian wall. Slight pressure on the ventral region of the fish caused the release of oocytes from the anal opening (Fig. 2c). Little adipose tissue was found associated with the gonads.

Similar data was observed in the ovary maturity stages of Sardinella longiceps [15]. In the study, it was noted that as the ovary matures, asymmetry in size between the left and right gonad was common. Mature oocytes inside the ovary stretch the gonad, and thus an increase in the size of the ovary can be observed. Moreover, the color of the gonads also changes from pink or flesh-colored in early stages, yellow to orange in the maturing stages. The color observed in the ovaries is due to the accumulation of yolk in the mature oocytes prior to spawning. Furthermore, as the ovaries develop, the ovarian membrane thins out as a
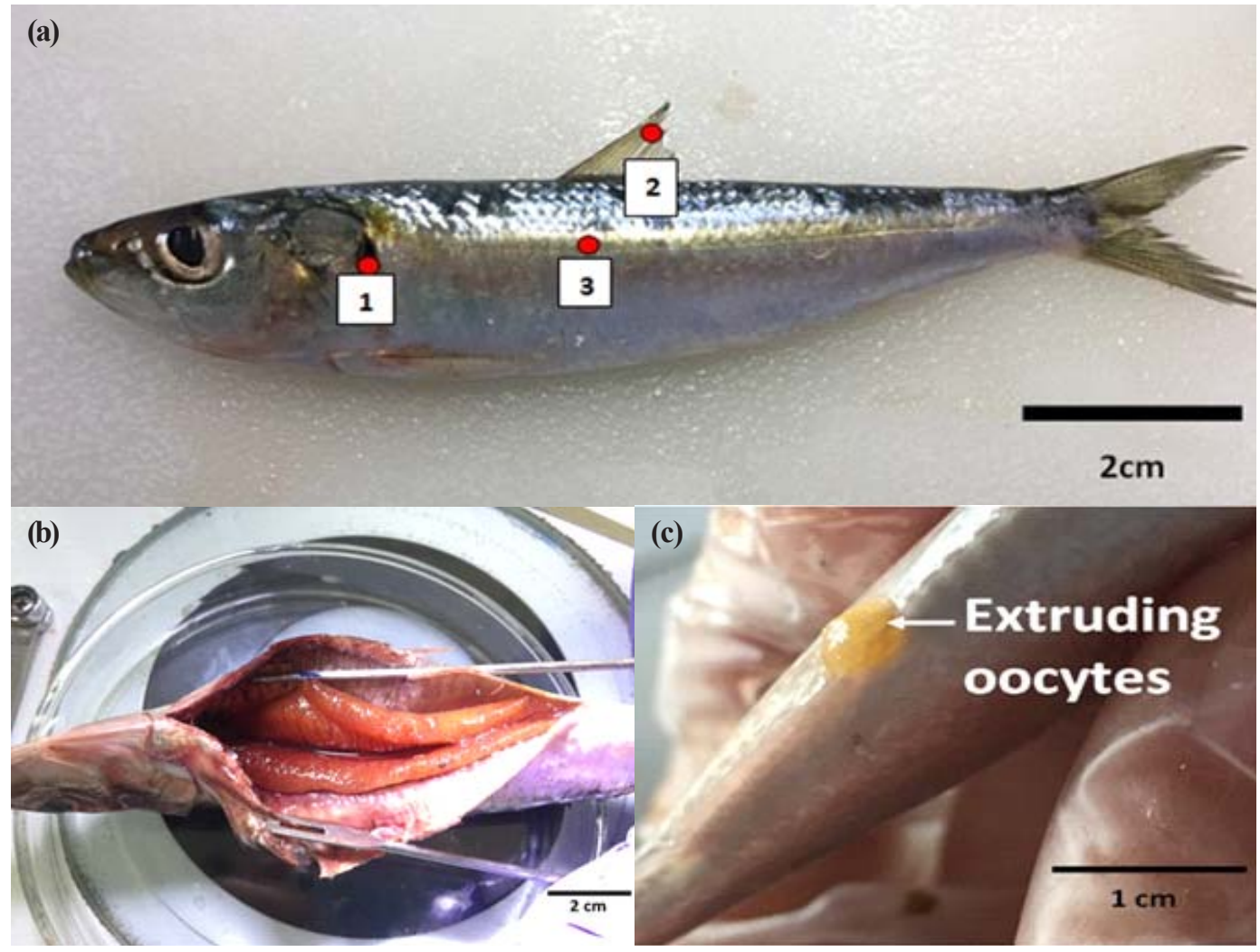

Figure 2. (a) Sardinella lemuru sample collected in December 2017: (1) black spot, (2) dorsal fin, (3) fait-golden mid-lateral line; (b) Mature ovary of S. lemuru sample; and, (c) Gravid S. lemuru showing extrusion of eggs from the anal aperture with slight pressure on the fish belly. 
result of the increase in size of the oocytes, making them more visible. This was also observed in the ovarian samples in S. lemuru. Blood vessels in mature ovaries are prominent. Ovarian membranes thin out as the oocytes became large, revealing the cells within.

Oocytes that are between $150-550 \mu \mathrm{m}$ in diameter are considered to be in their primary vitellogenic stage, while those that are at least $470 \mu \mathrm{m}$ in diameter are considered to be in their advanced yolked oocyte stage [12]. The presence of yolk granules that increase in number as the oocytes mature renders these cells opaque (Fig. 3). Our data show that secondary vitellogenic stage oocytes are at least $300 \mu \mathrm{m}$ in diameter. Hydrated oocytes, on the other hand, appear as large, translucent eggs that range from $600 \mu \mathrm{m}$ to $800 \mu \mathrm{m}$ [12]. The same characteristics were observed in the present work.

Gonadosomatic index. The GSI of the female fish samples were noted. The present data show that out of 42 female fish, 15 specimens were observed to have high values of $7-11 \%$ GSI. They were mostly present in the months of December and January. The highest mean GSI of $8.67 \%$ was noted in January. Those fish with relatively low gonad to body weight index (4$6 \%$ GSI) were collected during the months of November and February. The high GSI values in the samples during December and January indicate the peak in spawning activity. The observed spawning season of S. lemuru is similar to that recorded in Australia [16]. Our work records the spawning season from November to February while in the previous investigation, the spawning of the species in Western Australia occurred from December to March. The peak spawning in both studies was noted to occur nearly halfway through the spawning season, with late December to early January in Balayan Bay, and January to February in Western Australia. However, a different

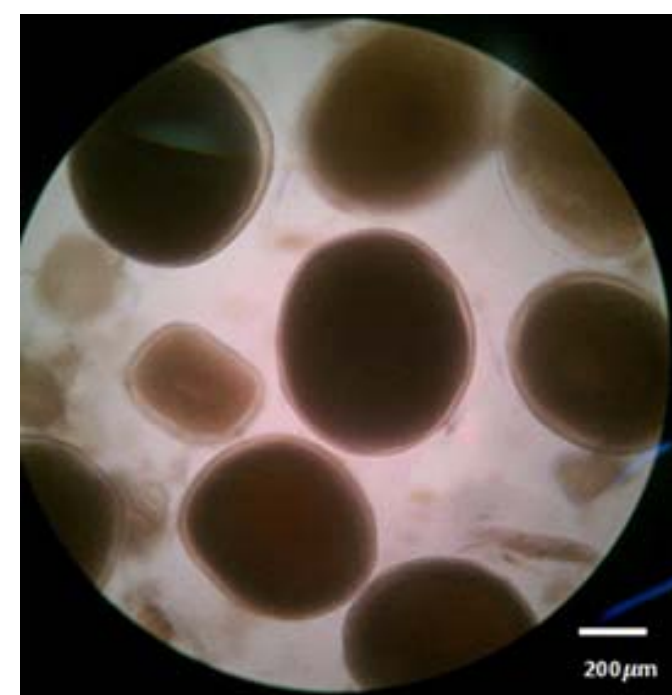

Figure 3. Oocytes in an ovarian subsample of $S$. lemuru

spawning season was recorded in Indonesia, which was from July to September, with the peak spawning activity occurring in September [17].

\section{Estimation of absolute, batch and relative} fecundity. Fecundity estimates were calculated for each fish. Only mature to gravid fish samples with GSI 4-11\% were considered for fecundity estimates. Oocytes that measured $300 \mu \mathrm{m}$ or larger were counted for estimating these parameters, following the criteria set by Hunter [12]. In the present work, the size of the oocytes counted ranged from $300 \mu \mathrm{m}$ to $700 \mu \mathrm{m}$ in diameter. Absolute fecundity ranged from 4,114 to 43,733 eggs $($ mean $=14.016+/-9,234)$. On the other hand, batch fecundity was noted to range from 1,035 to 25,560 eggs ( mean $=6,691+/-$ $5,902)$. Relative fecundity estimates show a range from 95 to 1,262 eggs/fish ( mean $=486+/$ $-225)$. Batch fecundity in our observations is close to that recorded for the species in Indonesia, where batch fecundity was estimated to be from 1,688 to 21,573 eggs per fish [17]. However, our data for batch fecundity is low compared to that recorded in Western Australia, where batch fecundity in S. lemuru was 

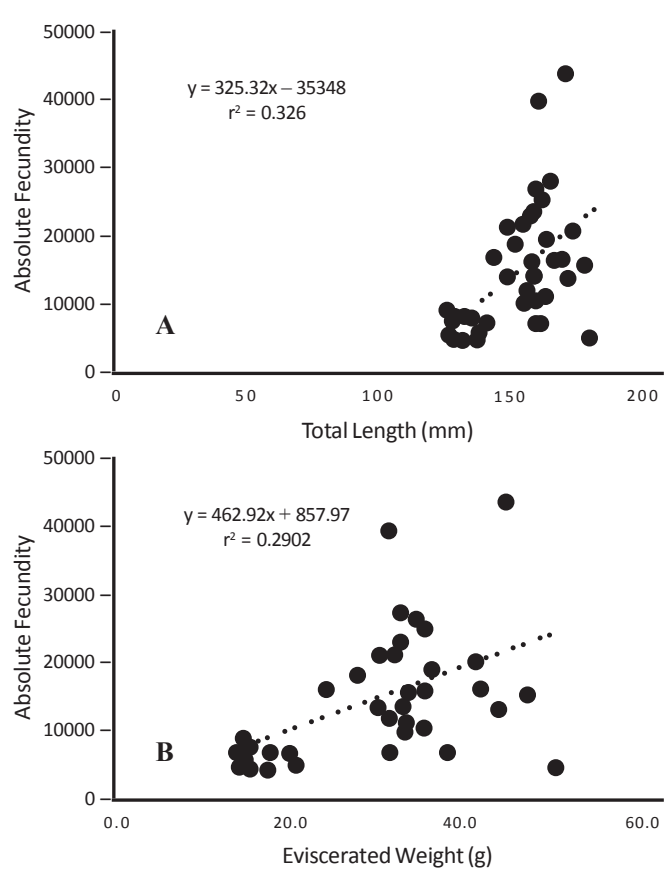

Figure 4. Relationship between (A) Absolute Fecundity versus Total Length ( $\mathrm{mm}$ ) and (B) Absolute Fecundity versus Eviscerated Weight (g) in S. lemuru.

estimated to be from 7, 248 to 40,710 eggs per fish [16]. Fecundity, which is a part of the maturation in a fish, is affected by the climate of the species' habitat [18]. It may differ in the same species, depending on the climate in the country where the fish is found.

\section{Relationship of fecundity with body length and} body weight. Linear regression was applied to understand the relationship between absolute fecundity and total length in S. lemuru (Fig. 4A). Total length exhibited linear relationship with absolute fecundity, with a regression coefficient value of $\mathrm{r}^{2}=0.0 .326$. Fecundity is expressed in the equation: $\mathrm{y}=325.32 \mathrm{x}-35348$, where $\mathrm{y}$ is equivalent to fecundity and $\mathrm{x}$ as the fish length. The same statistical analysis was used for the relationship between absolute fecundity with eviscerated weight (Fig. 4B). It was noted that in these two parameters being considered, absolute fecundity can be derived from the
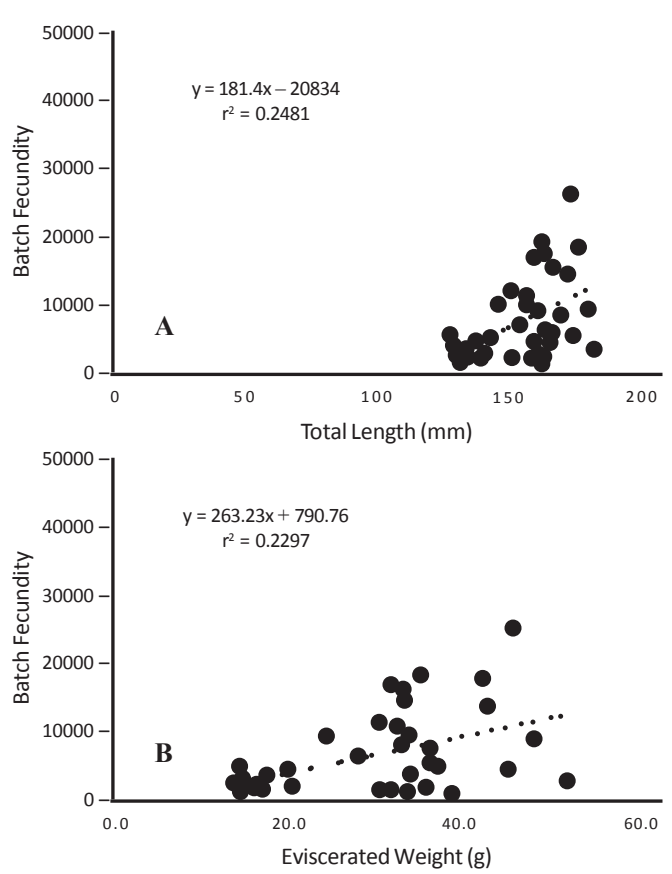

Figure 5. Relationship between (A) Batch Fecundity versus Total Length (mm) and (B) Batch Fecundity versus Eviscerated Weight $(\mathrm{g})$ in $S$. lemuru

equation, $\mathrm{y}=462.92 \mathrm{x}+857.97(\mathrm{y}=$ absolute fecundity, $x=$ fish weight). The regression coefficient value from the aforementioned relationship is $\mathrm{r}^{2}=0.29$.

Linear regression was also applied to assess the association between batch fecundity with total length and batch fecundity with eviscerated weight. The relationship between batch fecundity and total length is shown in the formula $\mathrm{y}=181.4 \mathrm{x}-20834(\mathrm{y}=$ absolute fecundity, $\mathrm{x}=$ fish weight) and $\mathrm{r}^{2}=0.23$ (Fig. 5A). For batch fecundity and eviscerated weight (Fig. 5B), the association was estimated from the equation $\mathrm{y}=263.23 \mathrm{x}-790.76$ (where: $\mathrm{y}=$ absolute fecundity, $\mathrm{x}=$ fish weight), $\mathrm{r}^{2}=0.23$. The present data on relationship between absolute fecundity and total length $\left(\mathrm{r}^{2}=0.0 .33\right)$ or eviscerated weight $\left(\mathrm{r}^{2}=0.29\right)$ indicate that there is a weak correlation between these parameters. A similar trend was also observed 
in the association between batch fecundity and total length $\left(\mathrm{r}^{2}=0.25\right)$, as well as that of batch fecundity and eviscerated weight $\left(\mathrm{r}^{2}=0.23\right)$.

These results are comparable to a previous research conducted on the fecundity of Brevoortia aurea [19]. In the aforementioned work, that there was no significant correlation with the fecundity on the weight or length of $B$. aurea. It should be noted that both $S$. lemuru and $B$. aurea belong to family Clupeidae, indicating that both species may share similar biological characteristics as far as fecundity is concerned. The weak correlation between absolute fecundity or batch fecundity with total length in the species may suggest that there may be fish with high fecundity values with a relatively shorter length compared to a longer fish. A similar pattern was also observed between absolute fecundity or batch fecundity with eviscerated weight in S. lemuru. The computed value may suggest that at a certain length, a maximum fecundity value may be reached, even when the fish grows longer and thus, heavier. Geographical features of an area can also influence the growth and maturity of the flora and fauna present within it [18]. Specifically, environmental temperatures can affect a population's rate of maturity. As the environment grows colder, its inhabitants grow slower, with their maturation being delayed and their lifespan prolonged. However, organisms living in warmer habitats mature faster and generally have shorter lifespan. In the present investigation, weather variations occurring during the collection of samples may have possible effects on fecundity and fish body length. It was noted that there was a difference in body weights (eviscerated weight) and lengths (total) between fish samples collected in 2015-2016 and those collected in 2017-2018 were observed. Fish weights ranged from $38.4 \mathrm{~g}$ to $41.8 \mathrm{~g}$ with a total length range of $150-181 \mathrm{~mm}$ in the previous collection (2015-2016). On the other hand, specimens collected from 2017-2018 showed a weight range of 13.8-45.1 g and 127-
$172 \mathrm{~mm}$ in total length. It should be noted that El Niño persisted from March 2015 to July 2016 [20]. The warm waters may have influenced the growth of the fish population, allowing them to be longer and heavier. In addition, occurrence of upwellings in the equatorial Western Pacific region throughout this phenomenon increased the net primary production due to higher availability of phytoplankton as well as zooplankton [21]. Sardines are known to be planktivorous [22], thus, there was more available food for the species during the aforementioned year. Fish samples that were collected during La Niña from December 2017 to March 2018 [23] was observed to be shorter and lighter due to a relatively colder water temperature and thus, less abundant prey for the fish species to feed on [21].

\section{Conclusion}

The present study is the first in-depth work on the fecundity of S. lemuru in the Philippines. Results of our invstigation on the fecundity of the species indicate that some fish with shorter lengths may have higher fecundity values compared to those with longer lengths. Furthermore, a maximum fecundity may be reached by a fish at a certain length, such that its fecundity will not increase even if the fish grows longer. Our data also shows a relatively high \% GSI from November to February, with peaks in December and January, indicate the spawning period in S. lemuru. Thus, the authors recommend that a longer closed season during the aforementioned months be implemented on the fishing of the species in Balayan bay. At present, a two-month (November to December) closed season for fishing $S$. lemuru is implemented [24]. Furthermore, the authors propose to conduct continued monitoring of the fecundity and other reproductive parameters on the species for its proper management. 


\section{ACKNOWLEDGMENTS}

The present research is part of an investigation on the reproductive biology of two sardines. The authors are grateful for the financial assistance of the Faculty Development Program, Office of Programs and Standards Development, Commission on Higher Education (CHED), the Research Center for Natural and Applied Sciencesand to the College of Science, University of Santo Tomas, Philippines.

\section{REFERENCES}

[1] Bureau of Agricultural Statistics (BAS). Agricultural Statistics 2011.

[2] Food and Agriculture Organization of the United Nations. Philippines at a Glance 2019. http:// www.fao.org/philippines/fao-in-philippines/ philippines-at-a-glance/en

[3] Barut NC, Mijares MD, Subade R, Armada NB, \& Garces LR. Philippine Coastal Fisheries Situation. In: Silvestre G, Garces L, Stobutzki I, Ahmed M, Valmonte -Santos RA, Luna C, Lachica-Alino L, Munro P, Christensen V, \& Pauly D, (Eds.) Assessment, Management and Future Directions for Coastal Fisheries in Asian Countries (WorldFish Center Conference Proceedings) 2003; 67(1), $120 \mathrm{p}$.

[4] Luceño AJ, Torres MA, Tabugo, SR, \& Demayo CG. Describing the Body Shapes of three populations of Sardinella lemuru (Bleeker, 1853) from Mindanao Island, Philippines Using Relative Warp Analysis. International Research Journal of Biological Sciences 2014; 3(6), 6-17.

[5] Willette D, Bognot E, Mutia M, \& Santos MD. Biology and Ecology of Sardines in the Philippines: A Review. BFAR Technical Paper 2011; Series $13,1-20$

[6] Mahrus M, Sumitro S, Widodo N, \& Sartimbul A. The Association between Genetic Variations and Omega-3 Production on Sardinella lemuru in Lombok Strait. Journal of Agriculture and Veterinary Science 2012; 1(6), 12-16.

[8] Echem R. Geometric Morphometric Analysis of Shape Variation of Sardinella lemuru. International Journal of Advanced Research in Biological Sciences 2016; 3(9), 91-97.

[9] De Guzman A, Jimenez C, Madula J, Macario A, Flores M, \& Garcia J. Climate-driven variation in small pelagic fisheries production in Northern Zamboanga and Bohol Sea: Potential Impact, vulnerability and local adaptive capacity,Naawan, Misamis Oriental. In: International Conference on Climate Change Impacts and Adaptation for Food and Environmental Security 2012.

[10] Murua H, Kraus G, Saborido-Rey F, Witthames P, Thorsen, A, \& Junquera S. Procedures to Estimate Fecundity of Marine Fish Species in Relation to their Reproductive Strategy. Journal of Northwest Atlantic Fishery Science 2003; 33, 33-54.

[11] Farley J, Davis T, Bravington M, Andamari, R, \& Davies C. Spawning Dynamics and Size Related Trends in Reproductive Parameters of Southern Bluefin Tuna, Thunnus maccoyii. PLOS ONE 2015; 10(5), 1-17. DOI: 10.1371/ journalpone. 0125744

[12] Hunter JR, Lo NC, \& Leong RJ. Batch Fecundity in Multiple Spawning Fishes. U.S. Dep. Comm. NOAA Technical Report 1985; 67-77.

[13] Hunter J, Macewiz B, Lo C, \& Kimbrell C. Fecundity, spawning, and maturity of female Dover sole Microstomus pacificus, with an evaluation of assumptions and precisions. Fishery Bulletin 1992; 90(1), 101-128.

[14] Pérez N, Figueiredo I, \& Lo NCH. Batch fecundity of Sardina pilchardus (Walb.) off the Atlantic Iberian coast. Boletin del Instituto Español de Oceanografia 1992; 8, 155-162.

[15] Raja ABT. On the maturity stages of Indian oilsardine, Sardinella longiceps Val., with notes on incidence of atretic follicles in advanced ovaries. Indian Journal of Fisheries 1966; 13(1\&2), 27-47.

[16] Gaughan DJ \& Mitchell RW. The biology and stock assessment of the tropical sardine, Sardinella lemuru, off the mid-west coast of Western Australia. Perth, Western Australia. In: Fisheries Western Australia Research Report (Fisheries Research \& Development Corporation) 2000; 119 , $136 \mathrm{pp}$

[17] Gina M. Study on reproductive lemuru (Sardinella lemuru Blk.) Gonad based development and size of fish in determining spawning season Waters in East Coast Siberut Island (Unpublished doctoral dissertation). (Graduate School Bogor, Institute of Agriculture, Indonesia, 2006).

[18] Silva A, Santos MB, Caneco B, Pestana G, Porteiro C, Carrera P, \& Stratoudakis Y. Temporal and geographic variability of sardine maturity at length in the northeastern Atlantic and the western Mediterranean. ICES Journal of Marine Science 2006; 63, 663-676. 
[19] Chondar SL. Fecundity and its role in the racial studies of Gudusia chapra (Pisces: Clupeidae). Proceedings of the Indian Academy of Science 1997; $86 \mathrm{~B}(4), 245-254$.

[20] PAGASA-DOST CADS \& CLIMPS. El Niño Update and Climate Outlook. (Quezon City: PAGASA, 2015).

[21] Damatac AlIM \& Santos MD. Possible Effects of El Niño on Some Philippine Marine Fisheries Resources. Philippine Journal of Science 2016; 145(3), 283-295.
[22] Papa RDS, Pagulayan RC, \& Pagulayan AEJ. Zooplanktivory in the Endemic Freshwater Sardine, Sardinella tawilis (Herre 1927) of Taal Lake, the Philippines. Zoological Studies 2008; 47(5), 535-543.

[23] PAGASA-DOST CADS \& CLIMPS. Climate Outlook April - September 2018. (Quezon City: PAGASA, 2018).

[24] Pa-a S. Batangas to enforce seasonal closure of fishing grounds next month October 12, 2018. https://www.pna.gov.ph/articles/1050906 